\title{
Magnet Attract Shell during Head and Neck Surgery
}

\author{
Ahmed Khalaf Rabeea \\ M.B.CH.B High Diploma Otolaryngology, Department of Otolaryngology, Salahaden General Hospital, Tikrit, Iraq \\ Email: drahmedk600@gmail.com
}

How to cite this paper: Rabeea, A.K. (2019) Magnet Attract Shell during Head and Neck Surgery. International Journal of Otolaryngology and Head \& Neck Surgery, 8, 171-179.

https://doi.org/10.4236/ijohns.2019.85019

Received: June 6, 2019

Accepted: August 30, 2019

Published: September 3, 2019

Copyright () 2019 by author(s) and Scientific Research Publishing Inc. This work is licensed under the Creative Commons Attribution International License (CC BY 4.0).

http://creativecommons.org/licenses/by/4.0/ (c) (i) Open Access

\begin{abstract}
Objective: New method to use magnet for localization and extraction of shell during head and neck surgery. Method: Series of 3 cases study all are boy's 17_15_5 years old respectively. All are with penetrating shell injuries to head and neck in Salahaden General Hospital-Tikrit city-Iraq from 25-Oct.-2016 to 30 March 2017. This hospital is a central general governmental hospital that receives referral cases from region distal to the center of Salahaden province at north of Baghdad city (capital of Iraq) and plays a major rule in management of injured patient during war. The cases are selected after explanation of this new method to the patients, it is expected result, risk, possible complication, and unexpected sequelae that may happen after surgery. Prior consent from patients and their families about this sort of surgery has been got. These patients are from families of low socio economic group except the last one he is medium class. All are undergoing surgical management with the aid of magnet. Result: we have 3 cases of shell injuries to head and neck magnet is used successfully for identification of shells and helps in their extraction. Our trial is limited for metallic objects and limited depth. Conclusion: These results suggest that magnet aid removal of shell during head and neck surgery, is less invasive technique, minimal trauma to the surrounding tissues and reducing time of surgery.
\end{abstract}

\section{Keywords}

Magnet, Shell Injuries, Head and Neck

\section{Introduction}

In IRAQ because of war against terrorism there is an increase incidence of shell injuries between civilian and military persons. Shell injuries of head and neck represent complex management challenge because main blood vessels and vital structures are at risk, which include:

- Skull, facial bones and vertebrae. 
- Brain spinal cord and cranial nerves.

- Major blood vessels (carotid and jugular).

- Aero digestive tract.

- Sense organ (vision, hearing, olfaction and taste organ).

- Skin, muscles and soft tissue.

All penetrating injuries to head and neck that breach the platysma muscle are potentially dangerous and may require emergency treatment because of presence of vital structure in the neck which can injure.

Careful evaluation of injured patient by clinical examination, X ray, CT scan, angiography and duplex sonography is necessary for the decision of management.

We have faced different types of head and neck injuries, also, patients with multi organs injuries that necessitate team work management.

With selective approach, sever active bleeding, hypovolemic shock not controlled by resuscitation, rapidly expanding hematoma, large blowing wound and major hemoptysis are indications for emergency surgery [1].

"Magnets have been used by humans since their discovery 10 centuries B.C. Their specific power and action have caused curiosity and fear at the same time" [2].

Recently practical medical application of magnet involved magnetic resonance imaging, physiotherapy and transcranial magnetic stimulation for patient has depression or Parkinsonism. Lastly, the attempts have been made to involve magnet in surgical instrumentation like experimentally mitral valve reconstructive surgery; magnet is used instead of scalpel in laparoscopic surgery. The use of magnet directly during head and neck surgery leads to reduction of time of surgery and minimizes the trauma to the tissue. This technique will probably further develop with progress of surgery.

\section{Method}

Small sterile magnet was used its length $2 \mathrm{~cm}$, its width $3 \mathrm{~mm}$ covered with plastic envelope. Sterilization was done either by autoclave or immersion in surgical antiseptic solution which used for surgical instrument (for 24-hour). This magnet can attract metallic subject across full thickness of book composed of 100 papers. Our trial is limited to metallic object with limited depth.

\section{Result}

All these 3 cases are male, they are from region far away from the general hospital, all are admitted to hospital. Investigation: $\mathrm{X}$ ray and CT scan were done for them. The details of information about the Patient and the site of injury are as shown in Table 1.

\subsection{Patient One}

Was 17 years old boy from Biji city which lies $40 \mathrm{~km}$ north from central hospital. With history of shell injury to the left side of face just below the angle of mandible the shell penetrating the soft tissue and hit the angle of mandible then settled 
Table 1. Detail of patients and their management.

\begin{tabular}{cccccc}
\hline $\begin{array}{c}\text { Patient no. } \\
\text { and Sex }\end{array}$ & Age & Inlet & End distention & Injury & Management and Result. \\
\hline 1) Male & 17 years & Left lat. Side of face & $\begin{array}{c}\text { Muscles of left } \\
\text { lat.pharyngeal } \\
\text { compartment }\end{array}$ & $\begin{array}{c}\text { Soft tissue injury and } \\
\text { mandibular angle injury }\end{array}$ & $\begin{array}{c}\text { Surgery with aid of magnet, extraction of } \\
\text { shell, patient discharged 4-days later. }\end{array}$ \\
2) Male & 15 years & Right lower eye lid & $\begin{array}{c}\text { Left.antral medial } \\
\text { wall posteriorly }\end{array}$ & $\begin{array}{c}\text { Rt.antral roof injured } \\
\text { (haemoantrum), penetrating } \\
\text { nasal septum, recurrent epistaxis }\end{array}$ & $\begin{array}{c}\text { Blood transfusion, then surgery } \\
\text { with aid magnet, extraction of shell. }\end{array}$ \\
3) Male & 5 years & Lt lat.side of face & $\begin{array}{c}\text { Impacted in bone } \\
\text { of roof of nasopharyx }\end{array}$ & No damage & $\begin{array}{c}\text { Surgery with aid of magnet, } \\
\text { removal of shells. }\end{array}$ \\
\hline
\end{tabular}

deep in the muscle at the left lateral pharyngeal compartment [Figure 1] causing painful swallowing (dysphagia) and difficulty on opening of patient mouth (trismus) [Figure 2]. This injury before 4-months duration. The surgery was carried out (at 25 October 2016) Under general anesthesia Patient on tonsillectomy position. Left tonsillectomy was done by dissection method for the patient [Figure 3], then I applied sterile magnet holed by artery forceps to the tonsellar bed. There was attraction between magnet and the shell which was still deep in the tissue.

I dissect superior constrictor muscle then I pull the shell by magnet its large about $2 \times 2 \mathrm{~cm}$. [Figure 4] Closure of wound by layers, with cover of antibiotic therapy. Post-operative patient did well and was discharged home at the third day after surgery. Follow for one year interval complete resolution was achieved.

\subsection{Patient Two}

15 years old boy from Hawijah city about $70 \mathrm{~km}$ to the east of Salahaden province, with shell injury to the right lower eye lid obliquely hit infra orbital rim (leads to hemorrhage inside right maxillary sinus) then penetrating nasal septum and settled within bone of medial wall of Left maxillary sinus [Figure 5, Figure 6] causing recurrent epistaxis. The patient reached our hospital after one month. He was anemic because of the bad management (in Hawijah city) because of poor facilities. CT was done for the patient and show the shell settled at the bone of the left medial antral wall [Figure 7].

The patient was received 2 pints of compatible blood for correction of anemia. After one week surgery was done for the patient (at 28 Feb. 2017). Under general anesthesia. Patient on head up tilt, I introduced magnet carried by artery forceps into the left nasal fossa direct attraction was happened with shell but it is strongly impacted into the bone of medial antral wall. By using of periosteal elevator, chiseling of the bone, release of the shell was achieved, then I pushed it to the post nasal space and was extracted by aid of magnet from oral cavity, [Figure 8].

\subsection{Patient Three}

5 years old boy from Sherqat city $120 \mathrm{~km}$ north to province exposed to mortar 


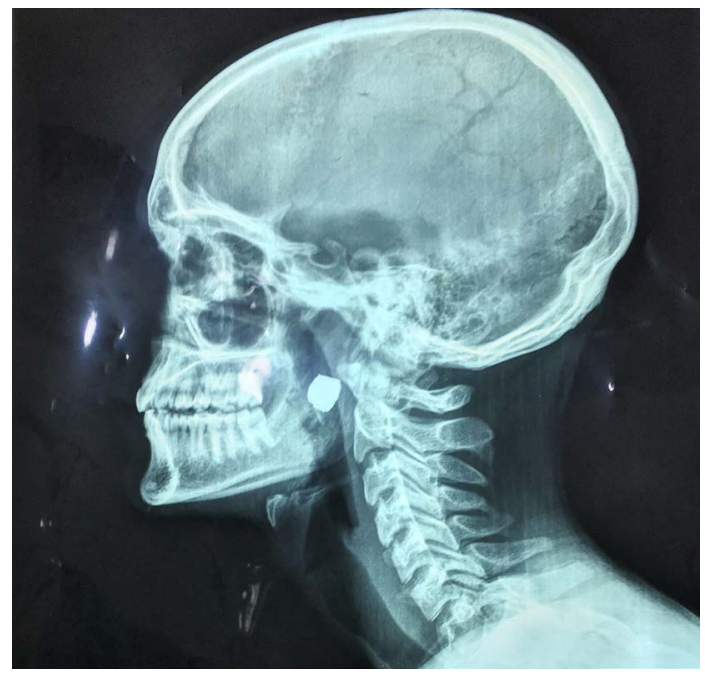

Figure 1. Shell injury from left side of face of young male penetrating soft tissue, injured left mandibular angle and settled at left lateral pharyngeal compartment.

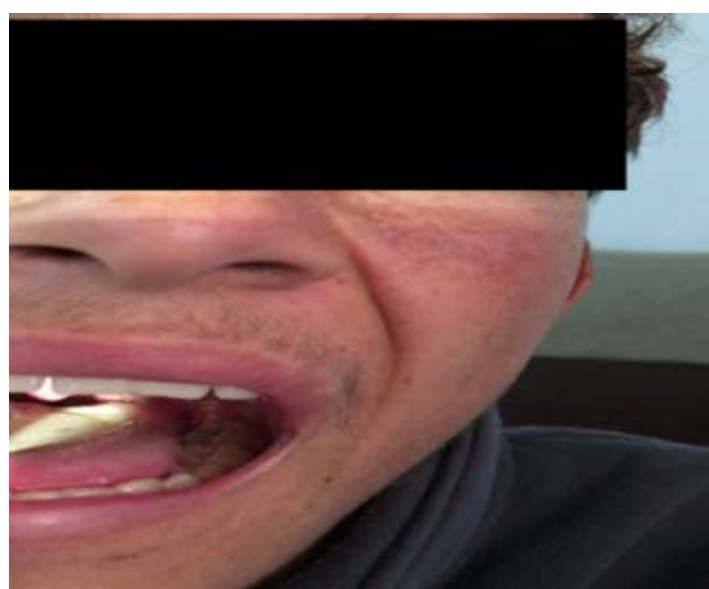

Figure 2. Figure young male with shell inlet from below angle of mandible penetrating tissue and settled deep to left tonsil causing painful swallowing (dysphagia) and difficulty on opening of patient mouth (trismus).

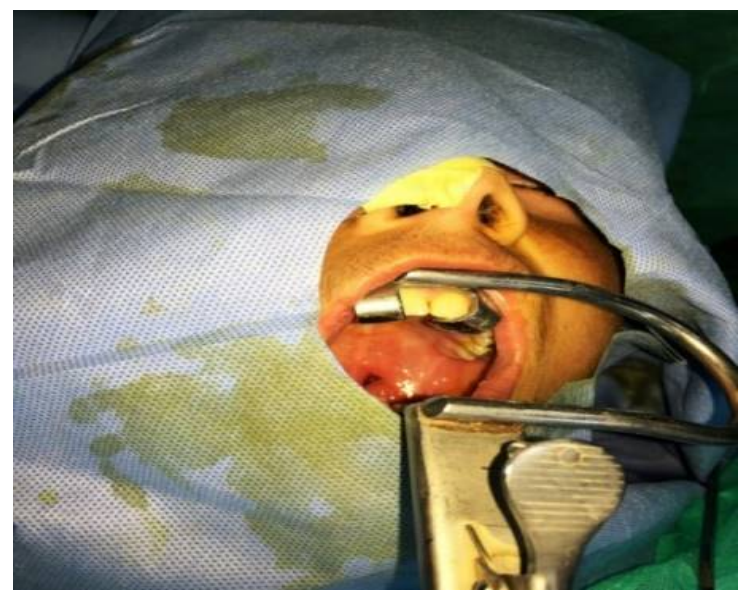

Figure 3. Left tonsillectomy by dissection method was done, then opening the of fascia and muscle to reach to the shell. 


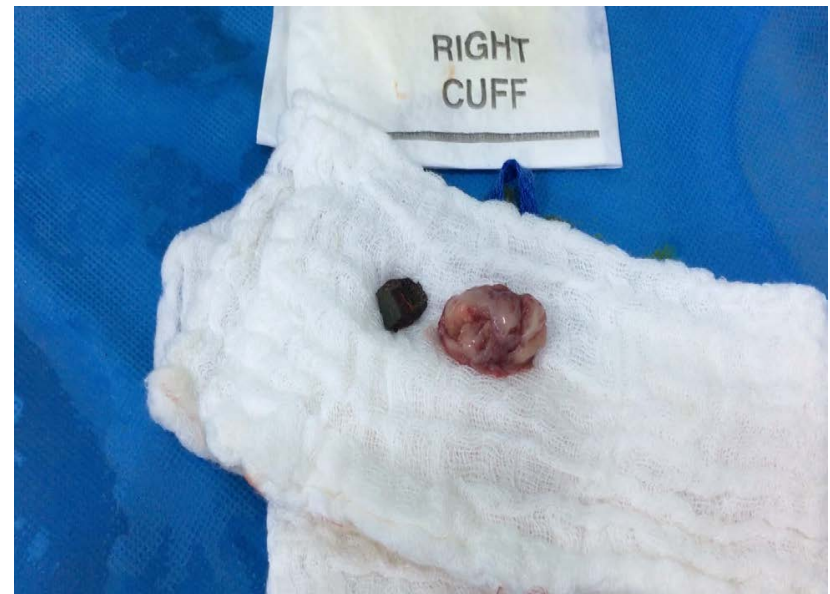

Figure 4. Left tonsile and the shell after removal.

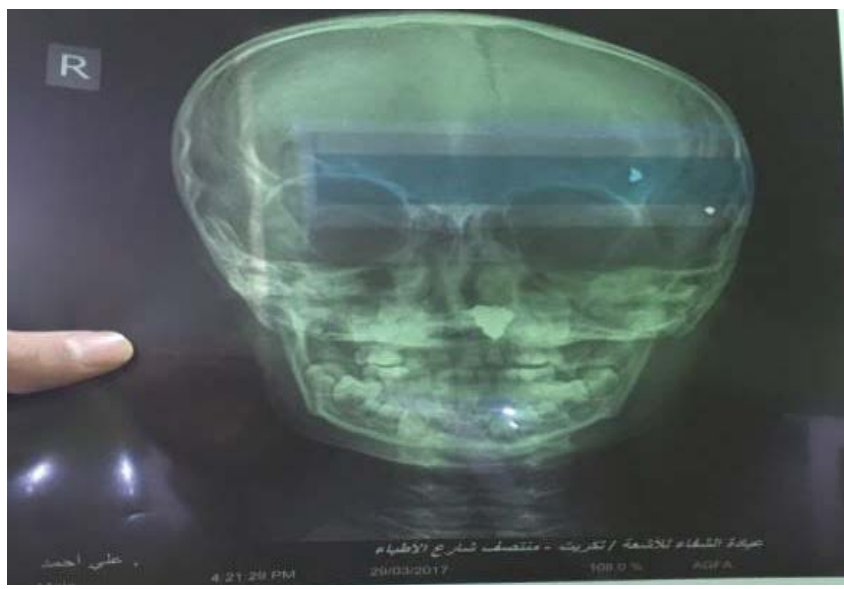

Figure 5. Antero Posterior view skull x ray showing shell at medial wall of left Antrum.

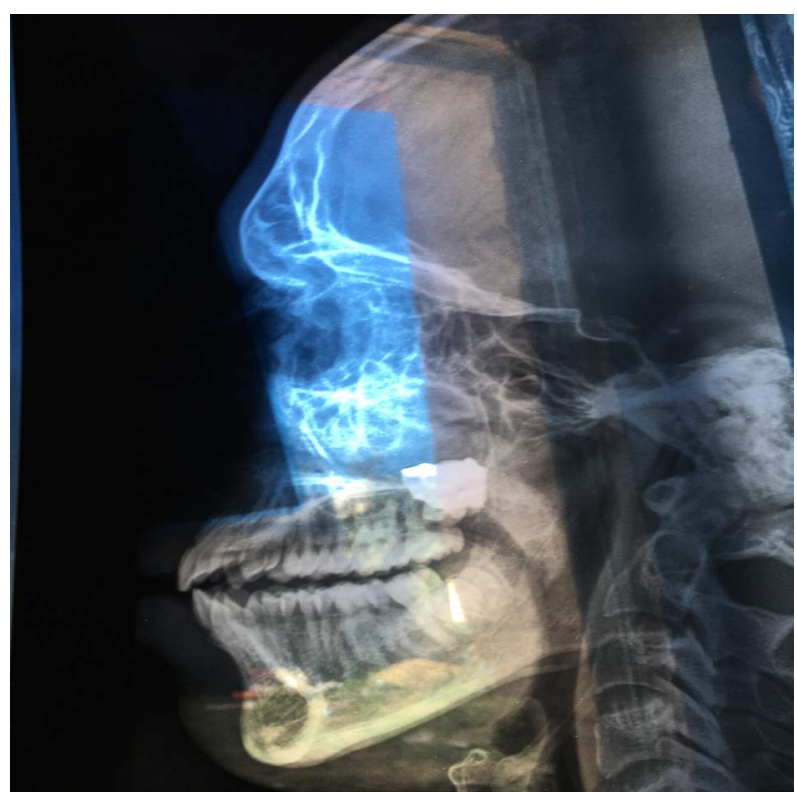

Figure 6. Figure lateral $\mathrm{x}$ ray for skull of the young male showing large shell impacted at the posterior part of the left nasal fossa. 


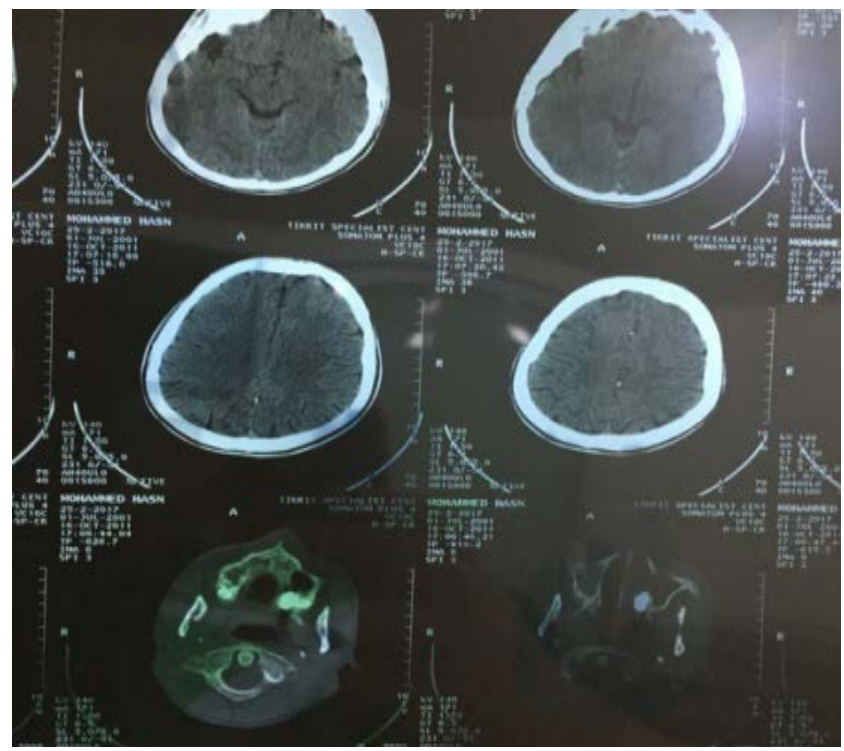

Figure 7. Figure Axial CT scan showing shell impacted at posterior part of the left medial antral wall.

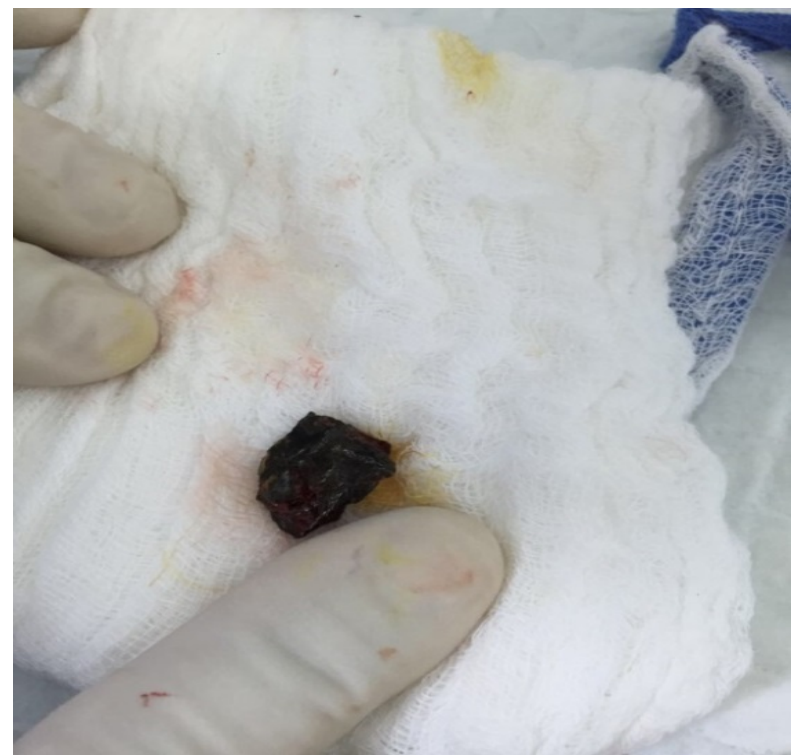

Figure 8. Shell after extraction.

injury to the left side of face penetrating soft tissue and settled at the roof of the nasopharynx partially impacted into the bone of the roof [Figure 9]. Radiology and laboratory Investigation was done for the patient. Surgery was done under general anesthesia (at 30 march 2017) Patient on tonsillectomy position. I applied sterile magnet it attract the shell but it is still impacted in. Simple manipulation by my hand, then magnet pull the shell and it is extracted From oral cavity [Figure 10]. Other small shell was removed by magnet from the region over left eye brows. Follow up for 2-years clinical examination, bleeding profile complete blood picture was done, The child was quite normal with no complication [Figure 11]. 


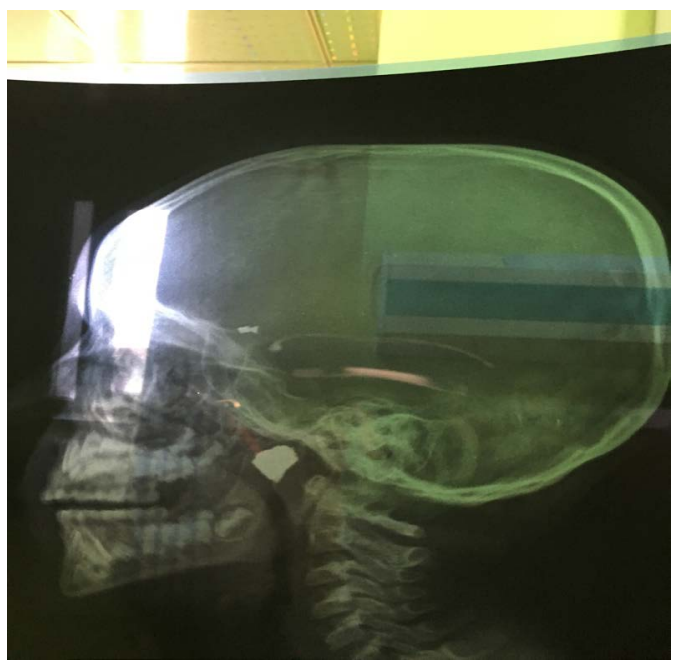

Figure 9. lateral $\mathrm{x}$ ray for the skull of the small boy showing shell embedded at soft tissue of the roof of nasopharynx.

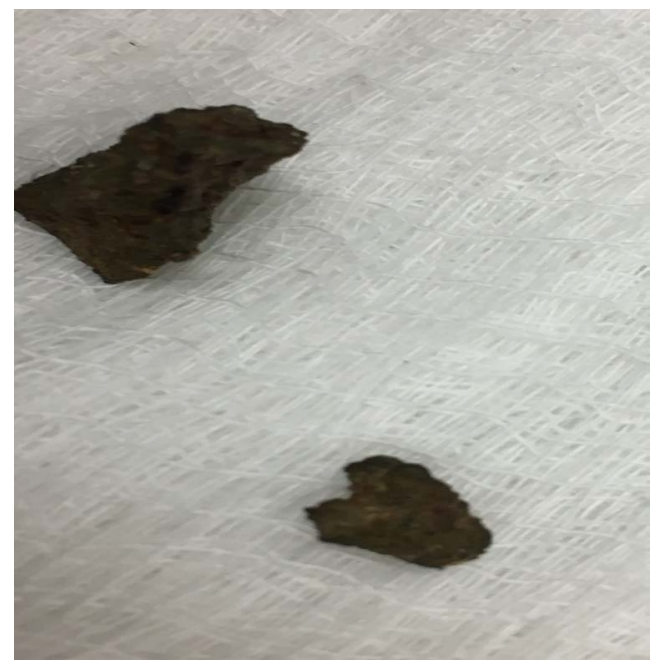

Figure 10. Show 2 shells after removal from roof of nasopharynx and left brows of the baby.

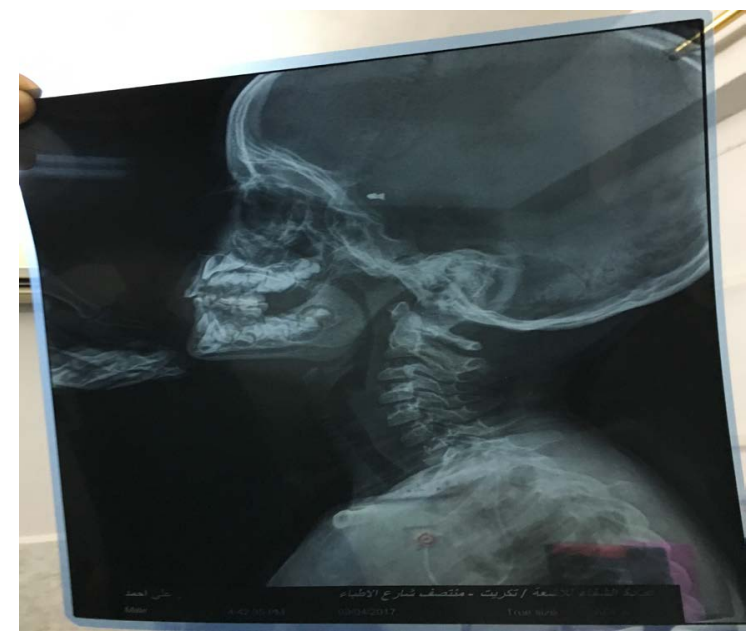

Figure 11. lateral skull $\mathrm{x}$ ray of the same patient after removal of the shell. 


\section{Discussion}

This is a new method to use magnet for localization and extraction of shell during head and neck surgery. I found it a helpful method. I have got benefit from magnetic attraction for removal of those shells (Figure 4, Figure 8, Figure 11) from difficult surgical site. And minimal surgical intervention was needed. Those three patients are lucky because even with dangerous injuries no vital structures are involved. Follow-up of the patients (clinical examination and blood sample for hemolysis) for more than one year shows no harmful effect to the patients. The aim of our trial is to find a new method for extraction of shell with limited incision, good orientation and should minimize mortality and morbidity. It is the first time to use magnet directly inside the wound, the magnet guides me to the shell and attracts it with minimal trauma to the surrounding tissue and reduces the time of surgery. If there are multiple shells inside the wound, magnet will attract all the shells except impacted but it guides us to its site. These trials are still in early stage of development yet but may allow similar procedure to be performed.

"The physical influence of stable magnetic fields upon the body results mainly from the influence upon the uncompensated electron spins, diamagnetic molecule (comprising liquid crystals contained in tissues), as well as moving electric charges. In case of application of constant magnetic fields, one should also consider the forces of ferromagnetic structure" [3].

Our patient had no physical signs of major vessels injury. Sometimes injury of major blood vessels might be tamponed by the foreign body therefore it is extraction that should be in proper condition to avoid severe bleeding. Penetrating foreign body in the neck needs selective exploration by many surgeons especially when sever bleeding, expanding haematoma, wound blowing and in cases of organic foreign bodies, early exploration and extraction to reduce chances of wound infection which is life threatening condition. But other surgeons prefer mandatory exploration

"It is also known already that the action of magnetic fields causes the regression of mental and physical fatigue symptoms, reduces irritability, as well as is effective in the treatment of depression manifestations" [4].

\section{Conflicts of Interest}

The author declares no conflicts of interest regarding the publication of this paper.

\section{References}

[1] Fagan, J.J. and Nicol, A.J. (2008) Neck Trauma. Seventh Edition, Scott-Browns Otorhinolaryngology Head and Neck Surgery Hodder Arnold, Vol. 2, 1769. http://www.hoddereducation.com

[2] Frask, M.M., Orłowski, A. and Notes, M. (2007) Natural Orifice Trans Luminal Endoscopic Surgery: Operacje przez naturalne otwory ciała. Videosurgery and Other Miniinvasive Techniques, 2, 98-102. 
[3] Laali, M., Flecher, E., Nogarede, B., et al., (2011) First Experimental Use of Magnets in Cardiac Valve Repair. Journal of Heart Valve Disease, 20, 169-176.

[4] Pasek, J., Mucha, R. and Sieron, A. (2006) Variable Magnetic Fields in the Treatment of Drug-Resistance Depression: Case Report. Balneologia polska, 8, 235-238. 